\title{
VOCATIONAL LEARNING: CONTRIBUTIONS OF WORKPLACES AND EDUCATIONAL INSTITUTIONS
}

Billett S (2007) Integrating contributions of workplace and college experiences in developing vocational knowledge In R McClean, D N Wilson \& C Chinien (eds) International Handbook on Education for the World of Work, UNESCO-UNEVOC - Springer Academic Publication, Dordecht, The Netherlands

\section{Stephen Billett, Griffith University, Australia}

\section{Vocational learning through work and college}

This chapter identifies contributions to the learning of vocational practice from experiences in both educational institutions and workplaces. It proposes that each of these setting potentially provides particular contributions to learning vocational practice. When each set of contributions is usefully exercised and integrated they stand to purposefully support rich and robust vocational learning. Yet, this integration is not possible in all circumstances. Therefore, it is important to understand the strengths and weaknesses of the contributions from both kinds of settings, and how best their learning potential can be maximised and their weaknesses limited. This paper is structured to achieve these purposes. Consideration is given first to the kinds of knowledge required to be learnt for effective vocational practice. Next, the contributions to learning vocational practices from both workplace and educational settings are discussed through a consideration of the strengths and weaknesses of their respective contributions. Consideration is then given to how best to integrate the contributions of both environments to provide optimum learning experiences.

\section{Goals for vocational practice}

Three kinds of educational goals are often associated with the learning vocational practice. There are: (i) generic skills required for work; (ii) the development of occupational specific knowledge; and (iii) the development of the skills required for particular workplaces. Generically applicable work competencies (e.g. Mayer, 1992; The Secretary's Commission on Achieving Necessary Skills (SCANS), 1992; EUROTECNET, 1994) are premised on a belief that, once secured, these competencies can be applied across all kinds of workplaces and work practices. Individuals developing skills in 'problem-solving', 'working in teams', 'communication', for instance, are claimed to be able applicable to a range of workplace contexts. However, this ambitious claim is yet to be proven, because workplace requirements are often highly specific and shaped by local requirements. So what constitutes generic or even occupational competence is situational. That is, the goals for learning are 
shaped by particular requirements, not just general workplace competencies (core skills). Hence, common workplace requirements (e.g. team work, problem-solving) only find form and can be judged in particular workplaces (Beven, 1997; Stevenson, 2002). So while these represent common requirements for performance at work they need to be contextualized in particular work settings.

The goal of developing occupational knowledge is that most commonly sought by vocational education systems. The concepts, procedures and dispositions required to practice an occupation (e.g. carpentry, plumbing, hairdressing, cooking) are identified through consultations with industry representatives and sometimes practitioners. These consultations lead to the development of national curriculum documents and standards, aimed to guide the teaching and assessment of occupational knowledge within national vocational education systems. These goals articulate the canonical requirements for practicising a particular occupation: the development of procedures, concepts and dispositions required for carpentry, nursing, motor mechanic, hairdressing etc.

However, on their own these national statements of occupational competence are not sufficient to elaborate how these requirements are manifested in particular workplace settings. For instance, the requirements for competent hairdressing practice are constructed quite differently across hairdressing workplaces (Billett, 2001a). Similarly, nurses’ work requirements differ across and within metropolitan hospitals' wards, country towns, or in remote communities, as do the motor vehicle mechanics' work across different kinds of garages (Billett, 1999).

A more situated view of workplace competence addresses both the specific requirements of workplace and emphasizes the diversity of those requirements within an occupational field as salient educational goals. From this perspective, relying on securing skills and understanding at the occupational level alone is insufficient. The skills required to practice within and across workplace settings are important for understanding both situational performance and adaptability of practice. Rather than being able to adapt or transfer occupational knowledge per se, the capacity for adaptability or transfer is premised on understanding variations of practice (Billett, 2001a). These outcomes cannot be learnt without engaging in workplace settings.

So both general workplace competencies and occupational knowledge requires contextualizing in particular workplace setting to be effective goals for robust vocational learning. How these goals might best be secured through the potential contributions of both experiences in workplaces and in education institutions stands as an important goal for appraising the worth of these settings.

\section{Learning through work}

A series of studies into learning through work (Billett, 2001b) propose that much of the vocational knowledge required for work performance is and can be learnt through everyday work activities. This is hardly a novel 
claim as across most apprenticeship schemes, for instance, the majority of the apprentices' indenture is taken up with workplace experiences. Also, most learning throughout working life likely arises through engagement in work activities. Moreover, for many workers, the workplace is the only location in which to learn their vocational knowledge, as no college-based provision is available or accessible. The contributions of workplaces to vocational learning suggest these contributions are threefold (Billett 2001b): (i) everyday work activities; (ii) direct guidance; and (iii) indirect guidance.

Firstly, learning occurs through engagement in work tasks in the workplace. Through engaging in goal-directed activities, such as work tasks, more than deploying their knowledge and capacities, individuals are also engaged in reinforcing, refining and transforming those capacities through their use. The kinds of learning individuals secure are person dependent and premised on the novelty of the activity for the individual and how they engage with those activities. Encountering a new task and engaging in it purposefully, can lead to new learning, because it extends what individuals know. Yet learning in the form of reinforcement and refinement (i.e. improving) is secured through performing familiar tasks. Through opportunities to practice and improve, individuals are making increasingly mature approximations of the tasks in which they are engaging (Anderson, 1982). So, there are important legacies (i.e. learning) arising from the deployment of individual's knowledge when engaging in and completing work activities.

Indeed, a key contribution to learning through work is the opportunity to reinforce and refine new learning through repeated practice, which leads to the improving and perfecting of these capacities.

Opportunities for significant authentic practice are usually only available, albeit gratuitously, in workplaces. Anderson (1982) refers to the process of compilation and automation arising from repeating the same activities until the procedures can be conducted without recourse to conscious thought. This permits the individual to use their conscious thought in planning for and monitoring their activities. This is an important contribution of the rehearsal that arises from everyday work activities. Opportunities for this kind of rehearsal are rarely available in education institutions. So, the first contributions of learning through work are those arising via everyday work activities engaging individuals in work-related goal-directed activities whose legacies include reinforcing, refining or extending work-related procedures and concepts. Because these activities are situated in particular work workplaces, these legacies likely reflect particular instances of practice.

Close guidance by more experienced co-workers comprises the support provided by more expert or experienced coworkers and constitutes the second key contribution. The sources of knowledge required for performance resides outside of the individual. Hence, it has to be accessed and constructed from these social sources. More experienced coworkers possess vocational knowledge and the forms of its application in the particular workplace. This guidance can provide direct insights, 
understandings and access to procedures that may be difficult for individuals to learn on their own (Billett, 2001b). These co-workers can assist learning by making the requirements for performance explicit (i.e. 'what we do here is') and making accessible to the learner about how and why the practice is undertaken in a particular way. This close guidance can comprise direct assistance and advice about how to conduct procedures, or to understand work related concepts. This is the traditional role of the more expert work are providing modelling, coaching and explanations to the novice (Collins, Brown, \& Newman, 1989). Through interactions and collaborations with more experienced co-workers, workplaces afford access to forms of vocational knowledge (i.e. concepts and procedures) that cannot be learnt through everyday activities alone.

The third contribution to learning vocational practice is through the more indirect guidance provided by workplaces. This includes the physicality of the workplace that provides clues about and cues for how work has to be practiced, the standards required and the means for conducting that work. Again, these external sources of knowledge are important for workplace performance. The workplace provides these resources gratuitously. Yet, they are contributions that need to be accessed through learners' engagement. In some cultures, this is the only kind of guidance available and the learning of skills takes place through observation and the trial and error based on observable models of practice (Pelissier, 1991). Typically, these instances of learning through observation and imitation feature little in the way of intentional teaching (Lave 1990). The potency of these indirect forms of learning support are probably not fully understood and underestimated.

The learning potential of workplaces, then, is constituted through the experiences they provide. This includes authentic workplace activities from which learning arises, practice, and opportunities to engage and be supported either directly or indirectly. Through practice, the kinds of skills required for work performance can be accessed, refined and reinforced. These kinds of opportunities to engage in practice are simply unavailable in education institutions. These experiences provide contributions to learning through close and indirect guidance, support and the opportunity to develop the skills through practice over time as part of everyday activities.

\section{Weaknesses of learning through work}

However there are limitations of learning through work activities and interactions. These include: (i) inappropriate learning; (ii) access to appropriate experiences; (iii) lack of understanding; (iv) reluctance by workers to share knowledge; (v) absence of expertise; and (vi) lack of interest by workers (Billett 2001b). These are now elaborated.

Some of the knowledge learnt through everyday work activity is inappropriate. It comprises bad habits, dangerous short cuts or uninformed practices. Also, there can be difficulties in accessing the kind of activities required to develop rich knowledge for workplace practices. Access to these activities and interactions may be inaccessible or unavailable. 
Therefore, weak, incomplete or uniformed learning can result. There can also be a lack of understanding about the goals required for workplace performance. For instance, the required outcomes of work activities may be difficult for workers to observe and understand. For instance, in studies of coalmining (Billett, 1993), the coal taken from the mine was washed in a coal-washing plant prior to being placed on trains to take a coal-loading terminal several hundred kilometers away where the coal is graded and loaded onto ships for export. However, the goals to which their work was directed, including reducing the amount of foreign matter in the coal they sent from the mine to the washing plant. Yet, unless coalminers understand what occurs in locations remote from theirs, then their work might not very effective. Indeed, a common comment from workers who have acquired their skills through everyday work is that they learn how things are done, but not why they are done in a particular way (Billett \& Rose, 1997). That is, understanding about work activities might not be secured.

Understanding of practice is crucial when change or variations to the routine work activities are required. Without understanding the processes and practices, crucial errors might occur.

Experienced co-workers may be uncooperative or unavailable. Experts or more experienced co-workers might be reluctant to assist others to learn the knowledge required for workplace performance (Billett, 2001b). Particularly in contested or unstable workplaces, more experienced workers may fear displacement from those who they have assisted to learn. There might also be an absence of expertise, particularly with activities that are novel to the workplace. For instance, new software or technology might require particular expertise to be available, because nobody in the workplace has rich understanding of these tasks. Therefore, unless processes are available to assist workers understand the processes and practices they are engaging in, then there may be problems with performing work tasks that are novel in some way. This is of particular concern when the knowledge required for performance is difficult to access because it is remote from observation and tactile engagement, as when technology obscured the operation of workplace procedures (Zuboff, 1988).

Finally, workers may be reluctant to engage in the effortful processes of learning the requirements for effective practice. Individuals are selective in the activities in which they engage, perhaps because they cannot see the relevance of expending effort. Yet, unless workers engage in the activities with interest and effort, their learning may be weak. Therefore, the direction and intensity of workers' engagement with the knowledge to be learnt is essential for rich learning to arise.

These sets of factors stand to limit the kinds and quality of learning arising through workplace experiences and by degree stand to weaken the strength of learning potential of workplace experiences.

\section{Improving workplace learning experiences}

It follows that improving the potential of workplace learning experiences can be found in maximizing the positive contributions identified earlier 
and enacting intentional workplace interventions to minimize or overcome the weaknesses just described. Overall, improving the learning potential of the workplace is seen to reside in the three kinds of interventions: (i) developing and enacting a workplace 'learning curriculum'; (ii) enacting guided learning strategies in the workplace; and (iii) engaging workers in critical reflection upon the workplace experiences.

A workplace 'learning curriculum' be organized to assist learners engage in a sequenced set of experiences that can develop their workplace knowledge. The concept of a 'learning curriculum' is taken from Lave (Lave, 1990) who identified a pathway of activities through which apprentices learnt tailoring. The apprentices progressed along a pathway of activities moving from tasks with low risk factors and accountabilities (e.g. finishing and ironing) where mistakes can be tolerated, through to tasks requiring higher levels of competence, and where mistakes came at a high cost. However, beyond considerations for production of garments, this pathway of activities was inherently pedagogical. The apprentices first worked on finishing and ironing garments that were almost complete. These activities provided opportunities to observe the standard required for finished work, and to which their own efforts would need to be directed (i.e. the goals for their work performance). The sequencing of activities is also pedagogic insofar as it develops initial skills and understandings before elaborating more complex and high-risk skills. Similarly, within hairdressing salons (Billett, 2005), the apprentices first learnt to engage with clients through negotiating with them about drinks first, then later they develop further their negotiating and communication skills through interactions while washing hair, rinsing out colours and chemicals. Then, they often work with more experienced hairdresser and observe how that hairdresser, interacts with clients and performs procedures, and be able to access close guidance in the development of procedures and understanding about hairdressing practice. Similarly, the hairdressing tasks the apprentices learn are structured in a way that develops capacities to perform tasks where a failure is not crucial, (i.e. they learn how to cut men's hair before women's) in the first instance, and then developing more elaborate skills through guided and carefully monitored practice.

So a pathway of pedagogically structured activities needs to be identified for each workplace that takes learners from engaging in activities of low accountability through to activities that are more crucial to the workplaces' operation. Along the way, there will be identified tasks that are difficult to learn. These are of the kind that likely requiring direct guidance from more experienced workers. For instance, workers in a food processing plant, as well as identifying the most appropriate sequence of work activities, those who recently acquired the skills were most able to identify particular work activities that were most difficult to learn (Billett \& Boud, 2001).

The second basis to improve workplace learning is to use guided learning strategies for developing the procedural and conceptual knowledge required for workplace performance. These strategies focus directly on the development of procedures or concepts (e.g. understanding) 
that wont be learnt without guidance. Modelling, coaching and scaffolding are effective for the development of procedures, whereas questioning, diagrams analogies and explanations seem more effective at developing understanding (Billett, 2001b).

A key requirement for guided learning is that the more experienced worker has the knowledge that needs to be learnt and is adept at guiding the learning experiences including being competent in the use of specific workplace learning strategies, such as those referred to above. In this way, the workplace expert or more experienced coworkers can assist the learning through guiding closely and working collaboratively with novices or less experienced coworkers as do tradespersons when assisting apprentices' learning. Beyond knowing how and when to apply the specific guided learning strategies, closely supporting the development of other workers' skills includes organising appropriately sequenced access to the knowledge (i.e. managing the learning curriculum), particularly those forms of knowledge that individuals would not learn alone (Billett, 2003a). Moreover, this guidance includes organizing and monitoring individual workers' progression along the pathway of activities comprising the workplace learning curriculum.

A third level of guidance is to engage in reflection upon workplace experiences in order to develop understanding that has application beyond the particular workplace and the particular point in time (Billett, 2001b). A workplace incident (e.g. accident, ruined product) might be used to help understand the cause of the incident and then encouraged these workers to think about where else such an incident might occur. That is, seeking to take learning from the specific workplace incidents and use these incidents to project and extend this learning to other circumstances and situations. This kind of reflection can assist in the development of practice that is adaptable to other circumstances and situations. It is these kinds of processes that can be used to apprise learners of what constitutes the canonical occupational knowledge and what are common workplace competencies.

So, in order to improve the learning potential of everyday workplace experiences is proposed that this can be achieved through organizing, monitoring, and assisting the progress of individuals along the workplace's learning curriculum. Organising the workplace curriculum comprises the following. First, organising and sequencing pathways of experience that take the novices through to those requiring expert performance. This pathway will be determined by the kinds of activities to be learnt, and what constitutes expert performance in the particular workplace. Also, it is necessary to develop the capacities of individuals in the workplace to guide the learning of others and to engage in active learning. Moreover, enacting workplace learning arrangements includes identifying opportunities for optimal learning. Of course, such arrangements are not generated without effort and require a set of workplace values that are supportive of the workplace, becoming a learning practice. 
Importantly, many of the components for making workplaces effective learning environments will likely exist in most workplaces. That is, the routine and new work activities and interactions in which workers engage, the expertise and experience of existing workers and the agency of all in the workplace to engage and learn through work, and the nuanced understanding about how best to learn and develop further understandings about the situated practice of the workplace. Added to these are opportunities for workers to practice and refine their capacities, and come together to share their ideas and develop those further through workplace meetings and interactions. Beyond what is likely to be available freely in workplaces, the enactment of guided learning by more experienced expert co-workers. Workplace guidance has been shown to be effective when used in overcoming some of the limitations identified above (Billett, 2001b). Moreover, this guidance is used to organize and monitor the progress of individuals along a pathway of workplace experiences (i.e. the learning curriculum) that will assist them become more competent. An expert or experience coworker who is open to sharing knowledge, developing the skills of co-workers, and the potential contributions of those who are less specifically skills best provides this guidance. Yet, in times of change, experts' knowledge is less certain and the gap between experts and novices may have closed. Fuller and Unwin (2003) note that in apprenticeships relationships between the tradesperson and the apprentice are being transformed by apprentices' specific knowledge of new technology that is unavailable to or unknown by some trade persons. So, the agency of the learner is active and needs also to play a leading role in guided learning process.

In sum, the workplace offers a range of contribution for individuals' learning of effective workplace practices and furnishes a set of bases to improve the learning potential of the workplace.

\section{Learning potential of educational institutions}

The contributions to learning vocational knowledge from participation in educational institutions is subject to factors that both support and can potentially inhibit the learning of effective practices. In overview, educational institutions' potential to assist this learning is premised on the sets of activities and interactions focused on the intentional learning of vocational knowledge. Like workplaces, it is through processes of affordance and engagement that learning proceeds. Yet, in some important ways, the experiences, activities and environment of educational institutions are substitute or inauthentic instances of the practices to which the knowledge learnt is to be applied. Therefore, a key concern about their potential is that the learning may be weakly aligned to the requirements of workplace practices.

The potential for learning vocational practice in education institutions is premised on the quality of the experienced curriculum: what students construe and construct (i.e. learn) from their experiences (Marsh \& Willis, 1995; Pinar, 1980). Perhaps central to these experiences are the activities of teachers and their interactions with students. As in 
workplaces, there is knowledge that is best acquired through direct teaching, including structured learning activities to develop crucial knowledge. Intentional instructional activities can be used to assist students understand concepts. Instructional activities and devices that reveal the processes operating inside an electric motor, automobile engine or structure of hair follicles do so in ways that are unlikely to be possible in workplace settings. Moreover, there are instructional strategies focused on developing procedures that also can be used in ways that could not be undertaken in workplaces. The structured activities and ordered practice associated with learning touch-typing, for instances, are unlikely to be available in many workplaces. Moreover, teachers' experiences (e.g. stories and explanations) can provide important links between educational institution and the workplaces where students will ultimately apply their college-learnt knowledge (Billett et al., 1999). So the: (i) contributions of direct teaching to develop content specific and more general aspects of vocational practice; (ii) capacity to learn practices and concepts in ways that are unlikely to be available in workplaces; and (iii) capacity to make links between what happens within an educational institution and the workplace are important contributions that educational institutions can make to vocational learning. These stand as key affordances supporting student learning.

Yet, there are weaknesses or limitations to learning experiences within education institutions, particularly in terms of their adaptation to other environments. Some of these are well known and understood and some of the pedagogic practices reviewed above are directed towards overcoming those limitations. Firstly, and perhaps most pervasively, knowledge and individuals' construction of it is often situationally embedded. But the embedding context of educational institutions is quite different from workplaces. So, there may be inherent difficulties in the abstraction of that learning from a particular context in which it has been learnt (e.g. education institutions) to another context (e.g. workplace). This problem is not restricted to vocational learning. Indeed, many of the strongest criticisms of education institutions is that supposedly highly generalisable forms of learning (e.g. numeracy) in fact does not transfer across settings (Raizen, 1991; Scribner, 1985). It seems that the differences in what constitutes literacy and numeracy in particular contexts is such that the application of school learnt literacy and numeracy elsewhere (e.g. workplaces) is often inhibited (Searle, 2002) because learners cannot make the connections between who numeracy is used in school contexts and those outside of them. Then, there is the issue of the emphasis of the particular educational institutional context, with its practices and requirements that may render knowledge formation to be quite specific and not open to transfer. In many ways, perhaps far more so for vocational learning than general education, the environment of education institutions provides experiences that are inauthentic in terms of the kind of settings and practices where what has been learnt is then applied. That is, the kind of activities and interactions that have such a powerful cognitive legacy are 
substitute - disembedded from those that occur in workplace settings (Billett, 2003b).

However, much knowledge transfers across settings, such as those from educational institutions to other practices. The capacity to communicate using vocabulary and written forms that are developed in education institutions attest to this, as does the application of school learnt procedures. Nevertheless, expectations about direct transfer of learning may be overstated and are best secured when intentional strategies and practices are deployed to generate learning that has links to practices beyond those in which they are learnt. Moreover, the diversity of vocational practice, even within the same occupation, is such that the requirements for effective performance is highly situated within each workplace (Billett, 2001a). This represents a significant and possibly impossible educational goal: to develop vocational learning that is applicable to diverse instances of vocational practice which are unknowable to those who designed the curriculum and those who teach students. Hence, the need to extend learning experiences beyond those available in workplace settings.

In seeking to address the limitations of experiences within education institutions, a common imperative arises. That is, how best can the contributions of educational institutions and the experiences that students have within them be exposed to or integrated with those in workplaces and work practices. The important point for learning vocational practice here is that whereas there are distinct contributions that arise from experiences within workplaces and educational institutions that the full potential for effective vocational learning is likely to be found in the integration of both kinds of experiences (i.e. those within the workplace and educational institutions). That is, bringing together the contributions of both of these settings and integrating them effectively in ways that promote robust vocational learning: learning not restricted to the circumstances of its acquisition.

\section{Integrating workplace and education institution experiences}

As a starting point, it seems likely that it will be those within educational institutions and systems (i.e. teachers and curriculum planners) who will lead the process of integrating the contributions of workplace and educational institutions. This is because much of the wherewithal, interest and emphasis resides within educational institutions (Billett et al., 1999). Also, it is educational institutions that need to deploy their greater understanding of pedagogy and curriculum in order to richly integrate the two sets of experiences. On balance, given the key role for supporting learning and the concerns about the applicability of what is learnt in educational institutions to workplace settings, it is also perhaps most in the interests of educational institutions to take leadership in supporting the integration of the two sets of contributions. However, a key issue here will be to overcome the narrow views of learning and legitimate environments for learning residing within educational institutions and the privileging of experiences within educational institutions. The following are 
combinations of pedagogic and curriculum practices that might be enacted to secure this integration. They are best placed to assist workplaces development of learning curriculum, guided learning strategies and critical reflection on practice. It is the rich sets of workplace experiences that need to be engaged within the educational institution.

In structured entry-level training programs, such as apprenticeships, students engage in extensive periods of work experience. In many apprenticeship systems this comprises between 80 and $90 \%$ of the apprenticeship. So, apprentices participating in the educational institution component of their initial preparation are engaged in extensive and diverse instances of work practice. These experiences offer rich bases for developing robust vocational learning. An important component of promoting this goal is to understand about diverse vocational practice and the different techniques required securing particular learning outcomes and understanding distinctions among those outcomes. Engaging students in discussing, sharing and evaluating their own and each other's experiences within the same occupation can generate different accounts of the application of their vocational learning. Further, it provides a platform for teachers to draw out canonical principles and practices that inform effective practice across the occupation. For instance, if groups of apprentices (e.g. builders, motor mechanics, hairdressers or electricians) were to discuss how particular tasks within building practices, automotive repair, hairdressing and electrical work are conducted in their workplaces and the reasons why those tasks are conducted in that particular way, students will be introduced to different approaches and different rationales for those approaches within the occupation. These experiences then can be utilised by the teacher to emphasise differences and or similarities across these practices and a diverse rationales for their use. Once students have an understanding of foundational skills and concepts, they may be prompted to understand the diverse rationales for particular approaches to similar workplace tasks and problems. They will be prompted to explore, not just the procedures learnt in the educational institution, but consider a diversity of possible options and approaches, depending upon the goal that is to be secured. The key pedagogic requirement here is for the teacher to facilitate this process, so students can appreciate and understand the importance of these variations in practices, and then draw out working principles and practices for these instances.

Relating content and principles taught through classroom experiences to workplace instances may also help to build links between classroom-learnt knowledge and that within workplaces. This does not mean that teaching has to be uncritical or reactive, but that the relevance and applicability of what is taught in classroom settings be projected to workplace practices in order to illustrate this content and test out its applicability to a range of workplace settings. However, seeking to engage students effectively in constructively reflecting on their practice may serve to assist the process of learning through their effortful engagement, rather than being positioned as passive recipients of the knowledge being taught. 
Such processes are aligned to those most likely to develop robust knowledge.

For those students without extensive work experience in their vocational field, it may be necessary to organise particular kinds and sequences of workplace experiences. In order to secure the best outcomes from these experiences their purposes and enactments need to be designed and organised effectively. These experiences also need to be organised to secure particular pedagogic or curriculum purposes. For instance, a first set of experiences might be focused on understanding the practice of the work undertaken within the particular vocational field. Hence, the work experience is organised to achieve those particular educational purposes. Students might engage in workplace experiences to understand the roles and scope of the occupation for which they are being prepared. Then, these experiences might be shared or elaborated on in teacher-directed activities within the education institution. Later, the intent of those experiences might be for the development of specific vocational knowledge. Here, the requirement for practice and support might be emphasised and these prioritised in your request to the workplace or activities back in the education institutions.

Curriculum processes here may need to be respectful of national frameworks and perceptions for vocational learning, but also be sensitive to and tolerant of situational and local differences in the application of vocational knowledge. That is, acknowledging and enacting curriculum provisions that are not based upon uniform national descriptions. Instead, they actively seek to understand the variations and manifestations of vocational practice in the kinds of workplaces in which the apprentices or students are currently engaged or will do so in the future can promote robust knowledge.

As individuals' engagement in the activities and interactions within both education institutions and the workplace are central to the quality of learning they secure, a different form of integrating the two sets of experiences is to identify and reinforce the commonality of purpose across the two sets of experiences. In particular, processes associated with developing the learner's identity as a vocational practitioner's may well be helpful in engaging them agentically and, potentially, the in learning more about their vocational practice.

However, having proposed these pedagogic and curriculum interventions, it is important to acknowledge that not all provisions of vocational learning include a component of experiences within educational institutions. Further, some have been restricted to the most minimal of encounters, through text based or web-based interactions. Moreover, both workplaces and educational institutions, although the latter are subject to most criticism, can only provide or afford experiences for integrating students' learning experiences. There is still scope for and responsibility within the learning arrangements individuals' engagement with the integrated experiences that are being afforded them. However, wherever possible, fundamentally those sets of experiences stand to be augmented and enriching by integration with the other. 


\section{Learning vocational practice}

It has been proposed here that experiences in both workplace and educational institutions when effectively integrated stand to develop generic, occupational and situational competence. Yet, even on their own the distinct contributions of both kinds of learning environment need to be understood and exercised effectively in assisting individuals learn vocational practice. It is through maximising the affordances of each environment and engaging learners richly with what each affords that offers the surest pathways to effective vocational learning.

\section{References}

Anderson, J. R. (1982). Acquisition of cognitive skill. Psychological Review, 89(4), 369-406.

Beven, F. (1997). Learning in the workplace: Airline customer service. Brisbane: Centre for Learning and Work Research, Griffith University.

Billett, S. (1993). Authenticity and a culture of workpractice. Australian and New Zealand Journal of Vocational Education Research, 2(1), 1-29.

Billett, S. (1999). Experts' ways of knowing. Australian Vocational Education Review, 6(2), 25-36.

Billett, S. (2001a). Knowing in practice: Re-conceptualising vocational expertise. Learning and Instruction, 11(6), 431-452.

Billett, S. (2001b). Learning in the workplace: Strategies for effective practice. Sydney: Allen and Unwin.

Billett, S. (2003a). Guiding vocational learning. In J. Stevenson (Ed.), Developing vocational expertise (pp. 226 - 246). Sydney: Allen \& Unwin.

Billett, S. (2003b). Vocational curriculum and pedagogy: An activity theory perspective. European Journal of Educational Research, 2(1), 6-21.

Billett, S. (2005). Constituting the workplace curriculum,. Journal of Curriculum Studies, 37(6).

Billett, S., \& Boud, D. (2001, 26-28th July 2001). Participation in and guided engagement at work: Workplace pedagogic practices. Paper presented at the 2nd International Conference on Learning and Work, Calgary.

Billett, S., McKavanagh, C., Beven, F., Angus, L., Seddon, T., Gough, J., et al. (1999). The CBT Decade: Teaching for Flexibility and Adaptability. Adelaide,: Nationla Centre for Vocational Education Research.

Billett, S., \& Rose, J. (1997). Developing conceptual knowledge in the workplace. Australian Journal of Adult and Community Education, 37(1), 12-26.

Collins, A., Brown, J. S., \& Newman, S. E. (1989). Cognitive apprenticeship: Teaching the crafts of reading, writing and mathematics. In L. B. Resnick (Ed.), Knowledge, Learning and 
Instruction, essays in honour of Robert Glaser (pp. 453-494). Hillsdale, N J: Erlbaum \& Associates.

EUROTECNET. (1994). Key/Core competencies- Synthesis of related work undertaken within the Eurotecnet programme (1990-1994). Brussels: European Commission.

Fuller, A., \& Unwin, A. (2003). Fostering workplace learning:Looking through the lens of apprenticeships. European Educational Research Journal, 2(1), 41-55.

Lave, J. (1990). The culture of acquisition and the practice of understanding. In J. W. Stigler, R. A. Shweder \& G. Herdt (Eds.), Cultural psychology (pp. 259-286). Cambridge, UK: Cambridge University Press.

Marsh, C., \& Willis, G. (1995). Curriculum: Alternative Approaches, Ongoing Issues. Englewod Cliffs: Merill.

Mayer, E. C. (1992). Employment-related key competencies for postcompulsory education and training - A discussion paper. Canberra, Australia: Australian Government Printing Service.

Pelissier, C. (1991). The anthropology of teaching and learning. Annual Review of Anthropology, 20, 75-95.

Pinar, W. F. (1980). The voyage out: Curriculum as the relationship between the knower and the known. Journal of Curriculum Theorizing, 2(1), 7-11.

Raizen, S. A. (1991). Learning and work: The research base. Vocational Education and Training for youth: Towards coherent policy and practice. Paris: OECD.

Scribner, S. (1985). Knowledge at work. Anthropology and Education Quarterly, 16, 199-206.

Searle, J. (2002). Situated literacies at work. International Journal of Educational Research, 37, 17-28.

Stevenson, J. (2002). Concepts of workplace knowledge. International Journal of Educational Research, 37, 1-15.

The Secretary's Commission on Achieving Necessary Skills (SCANS). (1992). Learning a living: A blueprint for high performance. Washington, DC: US Department of Labor.

Zuboff, S. (1988). In the age of the smart machine: The future of work and power. New York: Basic Books. 